\title{
Bacillus anthracis growth Inhibitory Properties of Australian Terminalia spp.: Putative Identification of low Polarity Volatile Components by GC-MS Headspace Analysis
}

\author{
Mitchell Henry Wright ${ }^{1}$, Joseph Sirdaarta ${ }^{1,2}$, Alan White ${ }^{1}$, Anthony Carlson Greene ${ }^{1}$, Ian Edwin Cock ${ }^{1,2^{*}}$ \\ 'School of Natural Sciences, Nathan Campus, Griffith University, 170 Kessels Rd, Nathan, Queensland 4111, AUSTRALIA. \\ 2Environmental Futures Research Institute, Nathan Campus, Griffith University, 170 Kessels Rd, Nathan, Queensland 4111, AUSTRALIA.
}

\begin{abstract}
Introduction: Anthrax is a severe acute disease caused by Bacillus anthracis infections. If untreated, it often results in mortality. Many Terminalia spp. have documented therapeutic properties as general antiseptics, inhibiting the growth of a wide variety of bacterial species. This study examines the ability of selected Australian Terminalia spp. extracts to inhibit B. anthracis growth. Methods:Solvent extracts were prepared from Terminalia carpentariae and Terminalia grandiflora plant material and investigated by disc diffusion assay for the ability to inhibit the growth of an environmental strain of B. anthracis. Their MIC values were determined to quantify and compare their efficacies. Toxicity was determined using the Artemia franciscana nauplii bioassay. The most potent extracts were analysed by GC-MS headspace analysis. Results: T. carpentariae and T. grandiflora leaf, fruit and nut solvent extractions displayed good growth inhibitory activity against B. anthracis. Methanolic T. carpentariae leaf and T. grandiflora nut extracts were particularly potent growth inhibitors, with MIC values of 74 and $155 \mu \mathrm{g} / \mathrm{mL}$ respectively. The $T$. carpentariae leaf ethyl acetate extract was also a good inhibitor of $B$. anthracis growth (MIC $340 \mu \mathrm{g} / \mathrm{mL}$ ). All other extracts were substantially less potent growth inhibitors. Interestingly, the $T$. carpentariae leaf extracts with growth inhibitory activity were nontoxic in the Artemia fransiscana bioassay, with $\mathrm{LC}_{50}$ values $>1000 \mu \mathrm{g} / \mathrm{mL}$. In contrast, the $\mathrm{LC}_{50}$ value $740 \mu \mathrm{g} / \mathrm{mL}$ reported for the methanolic $T$. grandiflora nut extract indicates low-moderate toxicity. Non-biased GC-MS phytochemical analysis of the most active extracts (methanolic T. carpentariae leaf and
\end{abstract}

T. grandiflora nut) putatively identified and highlighted several compounds that may contribute to the ability of these extracts to inhibit the growth of $B$. anthracis. Conclusion: The growth inhibitory activity of the methanolic T. carpentariae leaf and T. grandiflora nutextracts against B. anthracis indicates their potential for the treatment and prevention of anthrax. Furthermore, the lack toxicity of the T. carpentariae leaf and the low-moderate toxicity of the T. grandiflora nut extract, indicates that their use may extend to all forms of the disease (cutaneous, inhalation or gastrointestinal).

Key words: Combretaceae, Terminalia carpentariae, Terminalia grandiflora, Wild peach, Native almond, Anthrax, Metabolomic profiling.

\section{Correspondence:}

Dr. Ian Edwin Cock,

School of Natural Sciences,

Environmental Futures Research Institute,

Nathan Campus, Griffith University,

170 Kessels Rd, Nathan,

Queensland 4111, AUSTRALIA.

Tel no.: +61 7 37357637; Fax no: +61 737355282.

Email: I.Cock@griffith.edu.au (I. E. Cock)

DOI : 10.5530/pj.2016.3.18

\section{INTRODUCTION}

Bacillus anthracis is a gram-positive, endospore-forming bacterium and is the etiological agent of the disease anthrax. The disease has extensive implications in the livestock industry through the infection of grazing animals, however it is perhaps most commonly associated with its use in bioterrorism. ${ }^{1}$ The most notable recent instance of weaponised anthrax occurred in 2001: B. anthracis spores were mailed to several locations in the U.S. and resulted in the infection of many people. ${ }^{2}$ However, inadvertent mass infections can be traced as far back as ancient Egypt and it is theorised that the plagues described in ancient literature may have been anthrax mass infections. ${ }^{3}$ Human anthrax is relatively rare compared to other vertebrates, and indeed outbreaks in both wildlife and livestock are a significant health and economic issue in many parts of the world. ${ }^{4}$ Anthrax infection in humans occurs when $B$. anthracis endospores enter the body through inhalation, ingestion or through abrasions in the skin., ${ }^{5,6}$ Once internalised, the body elicits an immune response, however the encapsulating endospore coating provides protection for the bacterium and can contribute to germination (via a process known as macrophageenhanced germination). ${ }^{7}$ The bacterium then resumes normal metabolic function and toxins are subsequently produced. Inhalation anthrax is the most dangerous of the three forms of the disease and infection via this pathway often results in death unless rapid treatment is administered.
Current strategies for the treatment of anthrax rely on the administration of both oral and intravenous antibiotics. Although vaccines have been available since the $19^{\text {th }}$ century, they must be administered prior to infection and are generally ineffective in the treatment of anthrax once infection has initiated. ${ }^{8}$ Whilst current antibiotic treatments are effective, due to the nature of antibiotics there is an inherent risk of $B$. anthracis conferring drug resistances and thus it is important to search for new antibiotics. ${ }^{9}$ Antibiotic therapy development may occur via the design and synthesis of new chemical agents, and also through the investigation and discovery of natural resources for use as antimicrobial agents. Furthermore, the development of novel anti- $B$. Anthracis products that could disinfect contaminated sites without the use of harsh chemicals offers an effective, safe alternative of decreasing the spread of the disease. Plants of the genus Terminalia have extensive therapeutic uses in multiple traditional healing systems, including uses for the prevention andtreatment of pathogenic diseases. Multiple studies have reported the antibacterial properties of Terminalia species used in traditional Indian medicine. Leaf and bark extracts of Terminalia arjuna have growth inhibitory activity against a wide panel of microbes. ${ }^{10,11}$ Terminalia chebula also has a tradition of use in Ayurveda for the treatment of numerous diseases and conditions ${ }^{12-14}$ and has also been reported to display potent 
antibacterial activity against a microbial panel. ${ }^{15}$ Similarly, Terminalia alata, Terminalia bellirica and Terminalia catappa have also been reported to have broad spectrum antibacterial activity. ${ }^{11}$ Numerous African Terminalia species also have potent antibacterial activity. One study of the South East African species Terminalia stenostachya and Terminalia spinosa reported strong inhibitory activity against a broad spectrum of medicinally important bacteria including several Mycobacterium species, Streptococcus faecalis, Staphylococcus aureus, Vibrio cholera, Bacillus anthracis, Klebsiella pneumoniae, Salmonella typhi, Pseudomonas aeruginosa and Escherichia coli. ${ }^{16}$ The Southern African species Terminalia sericea and Terminalia pruinoides have similarly potent inhibitory activity against a broad panel of pathogenic ${ }^{17}$ and food spoilage bacteria, ${ }^{18}$ as well as against bacteria associated with autoimmune diseases. ${ }^{19,20}$ Terminalia brownii also has a history of usage in traditional eastern and central African medicinal systems, including usage for the treatment of diverse medicinal conditions including diarrhoea and gonorrhoea. ${ }^{21,22}$ Interestingly, a recent study also reported that the T. brownie was also a potent inhibitor of B. anthracis growth. ${ }^{16}$ The Australian Terminalia species Terminalia ferdinandiana also has strong antibacterial activity against an extensive panel of bacteria. ${ }^{23-26}$ Other Terminalia spp. which are endemic to the tropical northern regions of Australia also have a history of traditional therapeutic usage to treat microbial infections. ${ }^{27}$ However, few studies have rigorously evaluated their therapeutic potential. This study screened two Australian Terminalia species (T. carpentariae and T. grandiflora) for the ability to inhibit B. anthracis growth.

\section{MATERIALS AND METHODS}

\section{Plant source and extraction}

The Terminalia carpentariae leaf and Terminalia grandiflora fruit and nut (seed) plant materials used in this study were a kind gift from David Boehme of Northern Territory Wild Harvest. Voucher samples of all plant specimens have been stored at the School of Natural Sciences, Griffith University, Brisbane (Australia). The plant materials were comprehensively desiccated in a Sunbeam food dehydrator and dried materials stored at $-30^{\circ} \mathrm{C}$ for later use. Prior to usage, the materials were thawed and ground into a coarse powder. Individual $1 \mathrm{~g}$ quantities of the materials were weighed into individual tubes and $50 \mathrm{~mL}$ of deionised water, methanol, hexane, chloroform or ethyl acetate were added. All solvents were obtained from Ajax Australia and were AR grade. The deionised water was sterilised prior to use. The ground plant materials were individually extracted in each solvent for $24 \mathrm{~h}$ at $4^{\circ} \mathrm{C}$ through gentle shaking. The extracts were then filtered through filter paper (Whatman No. 54) under vacuum, followed by drying by rotary evaporation in an Eppendorf concentrator 5301. The resultant extract was weighed and redissolved in $10 \mathrm{~mL}$ deionised water (containing 1\% DMSO).

\section{Qualitative phytochemical studies}

Phytochemical analysis of each extract for the presence of alkaloids, anthraquinones, cardiac glycosides, flavonoids, phenolic compounds, phytosterols, saponins, tannins andtriterpenoids was achieved as per previously described assays. ${ }^{28-30}$

\section{Antibacterial screening}

\section{Environmental Bacillus anthracis strain}

An environmental strain of Bacillus anthracis was isolated as previously described. ${ }^{31}$ All growth studies were performed using a modified peptone/yeast extract (PYE) agar: $1 \mathrm{~g} / \mathrm{L}$ peptone, $1.5 \mathrm{~g} / \mathrm{L}$ yeast extract, 7.5 $\mathrm{g} / \mathrm{L} \mathrm{NaCl}, 1 \mathrm{~g} / \mathrm{L}$ ammonium persulfate, $2.4 \mathrm{~g} / \mathrm{L}$ HEPES buffer ( $\mathrm{pH} 7.5$ ) and $16 \mathrm{~g} / \mathrm{L}$ bacteriological agar when required. Incubation was at $30^{\circ} \mathrm{C}$ and the stock culture was subcultured and maintained in PYE media at $4^{\circ} \mathrm{C}$. The media nutrient components were supplied by Oxoid Ltd, Australia. The GenBank accession number for the 16S rRNA gene sequence for the isolate is KR003287.

\section{Evaluation of antimicrobial activity}

Antimicrobial activity of all plant extracts was determined using a modified disc diffusion assay. ${ }^{32,33}$ Briefly, $100 \mu \mathrm{L}$ of established Bacillus anthracis culture was grown in $10 \mathrm{~mL}$ of fresh PYE liquid media until it reached a count of $\sim 10^{8}$ cells $/ \mathrm{mL}$. A $100 \mu \mathrm{L}$ volume of bacterial suspension was spread onto PYE agar plates. The extracts were tested for antibacterial activity using $5 \mathrm{~mm}$ sterilised filter paper discs. Discs were subsequently impregnated with $10 \mu \mathrm{L}$ of the test extract, allowed to dry and placed onto inoculated plates. The plates were allowed to stand at $4^{\circ} \mathrm{C}$ for $2 \mathrm{~h}$ before incubation at $30^{\circ} \mathrm{C}$ for $24 \mathrm{~h}$. The diameters of the zones of inhibition were measured in millimetres and all measurements were to rounded to the closest whole millimetre. Each assay was performed in triplicate. Mean values ( \pm SEM) are reported in this study. Standard discs of ampicillin $(10 \mu \mathrm{g})$ and penicillin $(2 \mu \mathrm{g})$ were obtained from Oxoid Ltd, Australia and served as positive controls for antibacterial activity. Filter discs impregnated with $10 \mu \mathrm{L}$ of distilled water were used as a negative control.

\section{Minimum inhibitory concentration (MIC) determination}

The minimum inhibitory concentration (MIC) of each extract was determined as previously described. ${ }^{34}$ Briefly, the plant extracts were diluted in deionised water and tested across a range of concentrations. Discs were impregnated with $10 \mu \mathrm{L}$ of the test dilution, allowed to dry and placed onto inoculated plates. The assay was performed as described above and graphs of inhibition zones versus concentration were plotted for each extract. Linear regression was used to determine the MIC values.

\section{Toxicity screening}

\section{Reference toxin for toxicity screening}

Potassium dichromate $\left(\mathrm{K}_{2} \mathrm{Cr}_{2} \mathrm{O}_{7}\right)$ (AR grade, Chem-Supply, Australia) was prepared as a $4 \mathrm{mg} / \mathrm{mL}$ solution in distilled water and was serially diluted in artificial seawater for use in the Artemia franciscana nauplii bioassay.

\section{Artemia franciscana nauplii toxicity screening}

Toxicity was assessed using a modified Artemia franciscana nauplii lethality assay ${ }^{35-37}$ Briefly, $400 \mu \mathrm{L}$ of seawater containing $\sim 43$ (mean 43.2, $\mathrm{n}=155$, SD 14.5) A. franciscana nauplii were added to wells of a 48 well plate and used for bioassay. A volume of $400 \mu \mathrm{L}$ of each diluted plant extract or the reference toxin were transferred to the wells and incubated at $25 \pm 1^{\circ} \mathrm{C}$ under artificial light (1000 Lux). A negative control $(400 \mu \mathrm{L}$ seawater) was run in triplicate for each plate. All treatments were performed in at least triplicate. The wells were checked at regular intervals and the number of dead counted. Nauplii were considered dead if no movement of the appendages was observed within $10 \mathrm{sec}$. After $24 \mathrm{~h}$ all nauplii were sacrificed and counted to determine the total \% mortality per well. The $\mathrm{LC}_{50}$ with $95 \%$ confidence limits for each treatment was determined using probit analysis.

\section{Non-targeted GC-MS head space analysis}

Separation and quantification were performed using a Shimadzu GC2010 plus (USA) linked to a Shimadzu MS TQ8040 (USA) mass selective detector system as previously described. ${ }^{23}$ The system was equipped with a Shimadzu auto-sampler AOC-5000 plus (USA) fitted with a solid phase micro-extraction fibre (SPME) handling system utilising a Supelco (USA) divinyl benzene/carbowax/polydimethylsiloxane (DVB/CAR/ PDMS). Chromatographic separation was accomplished using a 5\% phenyl, $95 \%$ dimethylpolysiloxane ( $30 \mathrm{~m} \times 0.25 \mathrm{~mm}$ id $\times 0.25 \mathrm{um}$ ) capillary 
column (Restek USA). Helium (99.999\%) was employed as a carrier gas at a flow rate of $0.79 \mathrm{~mL} / \mathrm{min}$. The injector temperature was set at $230^{\circ} \mathrm{C}$. Sampling utilised a SPME cycle which consisted of an agitation phase at $500 \mathrm{rpm}$ for a period of $5 \mathrm{sec}$. The fibre was exposed to the sample for 10 min to allow for absorption and then desorbed in the injection port for $1 \mathrm{~min}$ at $250^{\circ} \mathrm{C}$. The initial column temperature was held at $30^{\circ} \mathrm{C}$ for 2 min, increased to $140^{\circ} \mathrm{C}$ for $5 \mathrm{~min}$, then increased to $270^{\circ} \mathrm{C}$ over a period of 3 mins and held at that temperature for the duration of the analysis. The GC-MS interface was maintained at $200^{\circ} \mathrm{C}$ with no signal acquired for a min after injection in split-less mode. The mass spectrometer was operated in the electron ionisation mode at $70 \mathrm{eV}$. The analytes were then recorded in total ion count (TIC) mode. The TIC was acquired after a min and fora duration of 45 mins utilising a mass range of $45-450 \mathrm{~m} / \mathrm{z}$.

\section{Statistical analysis}

Data is expressed as the mean \pm SEM of at least three independent experiments.

\section{RESULTS}

\section{Liquid extraction yields and qualitative phytochemical screening}

Extraction of $1 \mathrm{~g}$ of the various dried Terminalia materials with the solvents yielded dried plant extracts ranging from $16 \mathrm{mg}$ ( $T$. grandiflora nut ethyl acetate extract) to $348 \mathrm{mg}$ ( $T$. carpentariae leaf methanolic extract) (Table 1). The leaf extracts generally gave relatively high yields of dried extracted material compared to the fruit and nut extracts. The dried extracts were resuspended in $10 \mathrm{~mL}$ of deionised water (containing $1 \%$ DMSO) resulting in the extract concentrations shown in Table 1.

Qualitative phytochemical studies showed that methanol and water extracted the greatest amount and widest range of phytochemicals (Table 1). These solvents extracted high levels of water soluble phenolics, moderate to high levels of tannins, as well as low levels of flavonoids and anthraquinones for all Terminalia samples tested. Saponins were also generally present in the methanolic and aqueous extracts, although the levels of this class of compound were more variable. The ethyl acetate extracts generally extracted similar but lower phytochemical profiles as the methanolic and aqueous extracts. In contrast, the chloroform and hexane extracts were devoid of detectable levels of all classes of phytochemical screened for.

\section{Antimicrobial activity}

To determine the ability of the crude plant extracts to inhibit the growth of $B$. anthracis, aliquots $(10 \mu \mathrm{L})$ of each extract were screened using a disc diffusion assay. The bacterial growth was inhibited by 7 of the 14 extracts screened (50\%) (Figure 1). T. carpentariae methanolic leaf extract was the most potent inhibitor of $B$. anthracis growth (as judged by zone of inhibition), with inhibition zones of $13 \pm 0.6 \mathrm{~mm}$. This compares favourably with the penicillin and ampicillin controls, with zones of inhibition of $8.3 \pm 0.6$ and $10.0 \pm 0.7$ respectively. The $T$. grandiflora methanolic nut and T. carpentariae methanolic leaf extracts both displayed good inhibition of $B$. anthracis growth, with $\geq 10 \mathrm{~mm}$ zones of inhibition. In general, the methanolic extracts were more potent inhibitors of $B$. anthracis growth than were their counterparts.

The antimicrobial efficacy was further quantified by determining the MIC values (Table 2). Several of the extracts were effective at inhibiting microbial growth, with MIC values against $B$. anthracis substantially $<1000 \mu \mathrm{g} / \mathrm{mL}(<10 \mu \mathrm{g}$ impregnated in the disc). The methanolic T. grandiflora nut and T. carpentariae leaf extracts extracts were particularly potent, with MIC values of 155 and $74 \mu \mathrm{g} / \mathrm{mL}$ respectively (approximately
1.6 and $0.7 \mu \mathrm{g}$ impregnated in the disc respectively). The T. carpentariae leaf ethyl acetate extract was also a potent inhibitor of $B$. anthracis growth (MIC value $340 \mu \mathrm{g} / \mathrm{mL} ; 3.4 \mu \mathrm{g}$ impregnated in the disc). The $T$. grandiflora fruit methanolic extract also had moderate growth inhibitory activity (MIC $3872 \mu \mathrm{g} / \mathrm{mL}$ ). All other extracts were either unable to inhibit B. anthracis growth, or only displayed low inhibitory efficacy (MIC values $>5000 \mu \mathrm{g} / \mathrm{mL}$ ).

\section{Quantification of toxicity}

All extracts were initially screened at $2000 \mu \mathrm{g} / \mathrm{mL}$ in the assay (Figure 2). For comparison, the reference toxin potassium dichromate $(1000 \mu \mathrm{g} /$ $\mathrm{mL}$ ) was also tested in the bioassay. Potassium dichromate was rapid in its onset of mortality, inducing nauplii death within the first $3 \mathrm{~h}$ of exposure and $100 \%$ mortality was evident following $4-5 \mathrm{~h}$ (results not shown). Most of the extracts displayed $>75 \%$ mortality at $24 \mathrm{~h}$.

To further quantify the effect of toxin concentration on the induction of mortality, the extracts were serially diluted in artificial seawater to test across a range of concentrations in the Artemia nauplii bioassay. Table 2 shows the $\mathrm{LC}_{50}$ values of the extracts towards $A$. franciscana. No $\mathrm{LC}_{50}$ values are reported for the T. grandiflora nut chloroform, hexane and ethyl acetate extracts, nor for the T. carpentariae leaf hexane extract as $<50 \%$ mortality was seen for all concentrations tested. Significant toxicity was noted for the T. grandiflora nut, fruit and leaf methanolic extracts, with $\mathrm{LC}_{50}$ values substantially $<1000 \mu \mathrm{g} / \mathrm{mL}$. All other extracts were determined to be nontoxic, with $\mathrm{LC}_{50}$ values substantially greater than 1000 $\mu \mathrm{g} / \mathrm{mL}$ following $24 \mathrm{~h}$ exposure. Extracts with an $\mathrm{LC}_{50}$ of greater than $1000 \mu \mathrm{g} / \mathrm{mL}$ towards Artemia nauplii have been defined as being nontoxic. ${ }^{38}$

\section{Non-targeted GC-MS headspace analysis Australian Terminalia extracts}

As the methanolic T. carpentariae leaf extract and the methanolic $T$. grandiflora nut extract had the most potent $B$. anthracis growth inhibitory efficacy (as determined by MIC; Table 2), they were deemed the most promising extracts for further phytochemical analysis. Optimised GCMS parameters were developed and used to examine the phytochemical composition of these extracts. The resultant gas chromatograms for the methanolic T. carpentariae leaf extract and the methanolic T. grandiflora nut extract are presented in Figures 3 and Figure 4 respectively. Major peaks were evident in the methanolic T. carpentariae leaf extract at approximately $11.1,12.9,14.4,17.0,18.2$ and 19.5 min (Figure 3 ). Several smaller peaks were also evident throughout all stages of the chromatograms. In total, 55 unique mass signals were noted for the methanolic T. carpentariae leaf extract (Table 3). Putative empirical formulas and identifications were achieved for 21 (38\%) of these compounds by comparison with the database.

The methanolic T. grandiflora nut extract was also a potent inhibitor of $B$. anthracis growth (as determined by MIC; Table 2) and was therefore also analysed by headspace GC-MS with comparison to a GC-MS spectral database. The resultant gas chromatogramis presented in Figure 4. Several major peaks were present at times which also corresponded to peaks in the T. carpentariae leaf extract chromatogram (11.1, 12.9, 14.4 and 19.5 min). Several smaller peaks were also evident throughout all stages of the chromatograms. In total, 28 unique mass signals were noted for the methanolic T. grandiflora nutextract (Table 4). Putative empirical formulas and identifications were achieved for 11 (39\%) of these compounds.

\section{DISCUSSION}

Many Terminalia spp. have a history of therapeutic usage to treat microbial infections and numerous recent investigations have reported on their 
Table 1: The mass of dried extracted material, the concentration after resuspension in deionised water and qualitative phytochemical screenings of the Terminalia extracts. $\mathrm{W}=$ aqueous extract $\mathrm{M}=$ methanolic extract; $\mathrm{C}=$ chloroform extract; $H=$ hexane extract; $E=$ ethyl acetate extract

\begin{tabular}{|c|c|c|c|c|c|c|c|c|c|c|c|c|c|c|c|c|}
\hline $\begin{array}{l}\frac{\tilde{u}}{\tilde{u}} \\
\text { ñ }\end{array}$ & 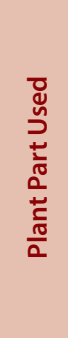 & 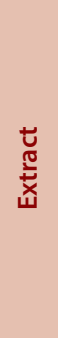 & 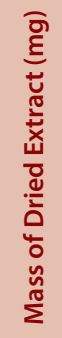 & 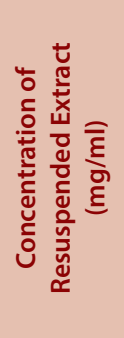 & $\begin{array}{l}\frac{\tilde{y}}{0} \\
\overline{0} \\
\frac{\tilde{J}}{a} \\
\frac{0}{\overline{0}} \\
\stackrel{0}{0}\end{array}$ & 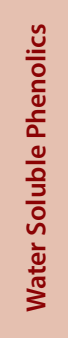 & 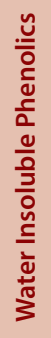 & 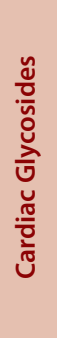 & 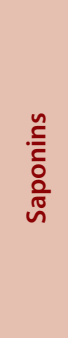 & 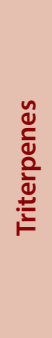 & 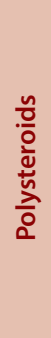 & 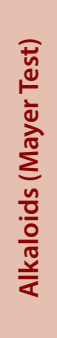 & 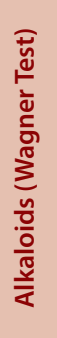 & $\begin{array}{l}\frac{n}{0} \\
\frac{0}{0} \\
\frac{0}{0} \\
\frac{\pi}{4}\end{array}$ & 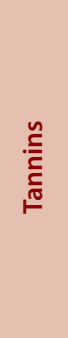 & 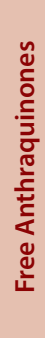 \\
\hline T. grandiflora & nut & $\mathrm{W}$ & 24 & 2.4 & +++ & ++ & - & - & ++ & - & - & - & - & + & ++ & + \\
\hline T. grandiflora & nut & $\mathrm{M}$ & 34 & 3.4 & +++ & ++ & - & - & +++ & - & - & - & - & + & ++ & + \\
\hline T. grandiflora & nut & $\mathrm{C}$ & 126 & 12.6 & - & - & - & - & - & - & - & - & - & - & - & - \\
\hline T. grandiflora & nut & $\mathrm{H}$ & 103 & 10.3 & - & - & - & - & - & - & - & - & - & - & - & - \\
\hline T. grandiflora & nut & $\mathrm{E}$ & 16 & 1.6 & + & + & - & - & - & - & - & - & - & + & + & + \\
\hline T. grandiflora & fruit & $\mathrm{W}$ & 80 & 8 & +++ & +++ & - & - & ++ & + & - & - & + & + & +++ & + \\
\hline T. grandiflora & fruit & $\mathrm{M}$ & 76 & 7.6 & +++ & +++ & - & - & +++ & + & - & - & + & + & +++ & + \\
\hline T. grandiflora & leaf & $\mathrm{W}$ & 179 & 17.9 & +++ & +++ & - & - & + & + & - & - & - & + & +++ & + \\
\hline T. grandiflora & leaf & $\mathrm{M}$ & 293 & 29.3 & +++ & +++ & - & + & ++ & + & - & - & - & + & +++ & + \\
\hline T. carpentariae & leaf & W & 180 & 18 & +++ & +++ & - & - & - & - & - & - & + & + & +++ & + \\
\hline T. carpentariae & leaf & M & 348 & 34.8 & +++ & +++ & - & + & + & - & - & - & - & + & +++ & + \\
\hline T. carpentariae & leaf & $\mathrm{C}$ & 200 & 20 & - & - & - & - & - & - & - & - & - & - & - & - \\
\hline T. carpentariae & leaf & $\mathrm{H}$ & 182 & 18.2 & - & - & - & - & - & - & - & - & - & - & - & - \\
\hline T. carpentariae & leaf & $\mathrm{E}$ & 42 & 4.2 & ++ & + & - & - & - & - & - & - & - & + & - & + \\
\hline
\end{tabular}

+++ indicates a large response; ++ indicates a moderate response; + indicates a minor response; - indicates no response in the assay.

Table 2: Minimum inhibitory concentration $(\mu \mathrm{g} / \mathrm{mL})$ of the plant extracts and $\mathrm{LC}_{50}$ values $(\mu \mathrm{g} / \mathrm{mL})$ in the Artemia nauplii bioassay. $W=$ aqueous extract $M=$ methanolic extract; $C=$ chloroform extract; $H=$ hexane extract; $E$ = ethyl acetate extract

\begin{tabular}{ccccc}
\hline Species & Part & Extract & MIC $(\mu \mathrm{g} / \mathrm{mL})$ & $\mathrm{LC50}(\mu \mathrm{g} / \mathrm{mL})$ \\
\hline T. grandiflora & nut & W & - & 1488 \\
T. grandiflora & nut & M & 155 & 740 \\
T. grandiflora & nut & C & - & - \\
T. grandiflora & nut & H & - & - \\
T. grandiflora & nut & E & - & - \\
T. grandiflora & fruit & W & 5380 & 3124 \\
T. grandiflora & fruit & M & 3872 & 370 \\
T. grandiflora & leaf & W & - & 1643 \\
T. grandiflora & leaf & M & - & 734 \\
T. carpentariae & leaf & W & $>10,000$ & 1336 \\
T. carpentariae & leaf & M & 74 & 1160 \\
T. carpentariae & leaf & C & - & 15358 \\
T. carpentariae & leaf & H & $>10,000$ & - \\
T. carpentariae & leaf & E & 340 & 1189 \\
Potassium Dichromate & - & - & & 82 \\
\hline
\end{tabular}

Numbers indicate the mean MIC and $\mathrm{LC}_{50}$ values of triplicate determinations. indicates no bacterial growth inhibition was evident, or that an $\mathrm{LC}_{50}$ value could not be obtained as the mortality did not reach $50 \%$ for any dose tested. 
Table 3: GC-MS headspace analysis of the $T$. carpentariae leaf methanolic extract, elucidation of empirical formulas and putative identification (where possible) of each compound

\begin{tabular}{|c|c|c|c|c|c|}
\hline Molecular Mass & Molecular Formula & Retention Time (min) & Area\% & Height\% & Putative Identification \\
\hline \multirow{3}{*}{151} & \multirow{3}{*}{$\mathrm{C}_{8} \mathrm{H}_{9} \mathrm{NO}_{2}$} & 11.094 & 24.64 & 19.58 & \multirow{3}{*}{$\begin{array}{l}\text { Methyl N-hydroxybenzene } \\
\text { carboximidoate }\end{array}$} \\
\hline & & 11.972 & 1.73 & 0.52 & \\
\hline & & 12.933 & 6.08 & 5.08 & \\
\hline 128 & $\mathrm{C}_{8} \mathrm{H}_{16} \mathrm{O}$ & 13.679 & 0.96 & 0.68 & 1-Octen-3-ol \\
\hline 126 & $\mathrm{C}_{8} \mathrm{H}_{14} \mathrm{O}$ & 13.94 & 1.2 & 1.01 & 5-Hepten-2-one, 6-methyl- \\
\hline 118 & $\mathrm{C}_{6} \mathrm{H}_{14} \mathrm{O}_{2}$ & 14.51 & 1.3 & 1.18 & 2-tert-Butoxyethanol \\
\hline 130 & $\mathrm{C}_{8} \mathrm{H}_{18} \mathrm{O}^{2}$ & 15.375 & 0.77 & 0.78 & 2-Ethyl-1-hexanol \\
\hline 146 & $\mathrm{C}_{6} \mathrm{H}_{10} \mathrm{O}_{4}$ & 15.512 & 1.45 & 1.03 & Dimethyl succinate \\
\hline \multirow[t]{2}{*}{138} & \multirow[t]{2}{*}{$\mathrm{C}_{9} \mathrm{H}_{14} \mathrm{O}$} & 16.444 & 0.2 & 0.25 & Isophorone \\
\hline & & 16.665 & 0.38 & 0.19 & \multirow{5}{*}{ a-Citronellol } \\
\hline \multirow{4}{*}{156} & \multirow{4}{*}{$\mathrm{C}_{10} \mathrm{H}_{20} \mathrm{O}$} & 16.881 & 0.76 & 0.81 & \\
\hline & & 17.331 & 0.42 & 0.21 & \\
\hline & & 17.445 & 0.13 & 0.06 & \\
\hline & & 17.877 & 0.91 & 1.02 & \\
\hline \multirow[t]{3}{*}{142} & \multirow{3}{*}{$\mathrm{C}_{9} \mathrm{H}_{18} \mathrm{O}$} & 18.065 & 1.48 & 1.97 & \multirow[t]{3}{*}{ Nonanal } \\
\hline & & 18.189 & 4.22 & 5.2 & \\
\hline & & 19.18 & 0.28 & 0.33 & \\
\hline \multirow[t]{2}{*}{152} & \multirow{2}{*}{$\mathrm{C}_{9} \mathrm{H}_{12} \mathrm{O}_{2}$} & 19.281 & 0.49 & 0.72 & \multirow[t]{2}{*}{ 4-Oxoisophorone } \\
\hline & & 19.45 & 0.35 & 0.49 & \\
\hline 150 & $\mathrm{C}_{9} \mathrm{H}_{10} \mathrm{O}_{2}$ & 20.061 & 0.47 & 0.61 & Ethyl benzoate \\
\hline 150 & $\mathrm{C}_{9} \mathrm{H}_{10} \mathrm{O}_{2}$ & 20.267 & 0.57 & 0.63 & Methyl benzeneacetate \\
\hline 154 & $\mathrm{C}_{10} \mathrm{H}_{18} \mathrm{O}$ & 20.731 & 0.14 & 0.21 & a.-Terpineol \\
\hline \multirow[t]{2}{*}{150} & \multirow[t]{2}{*}{$\mathrm{C}_{10} \mathrm{H}_{14} \mathrm{O}$} & 21.032 & 0.34 & 0.43 & \multirow[t]{2}{*}{$\begin{array}{l}\text { 2-Isopropylidene-3-methylhexa- } \\
\text { 3,5-dienal }\end{array}$} \\
\hline & & 21.104 & 0.16 & 0.22 & \\
\hline \multirow[t]{6}{*}{184} & \multirow[t]{6}{*}{$\mathrm{C}_{12} \mathrm{H}_{24} \mathrm{O}$} & 21.186 & 0.29 & 0.4 & Lauraldehyde \\
\hline & & 21.254 & 0.75 & 0.81 & \\
\hline & & 21.485 & 1.26 & 1.36 & \\
\hline & & 21.842 & 0.29 & 0.27 & \\
\hline & & 22.486 & 2.64 & 2.11 & \\
\hline & & 22.799 & 0.5 & 0.48 & \\
\hline & & 22.944 & 0.13 & 0.21 & \\
\hline 134 & $\mathrm{C}_{9} \mathrm{H}_{10} \mathrm{O}$ & 23.419 & 0.12 & 0.23 & 2,4-Dimethylbenzaldehyde \\
\hline & & 23.579 & 0.09 & 0.15 & \\
\hline & & 24.56 & 0.21 & 0.22 & \\
\hline & & 25.398 & 1.21 & 1.25 & \\
\hline & & 25.704 & 0.31 & 0.37 & \\
\hline & & 26.434 & 0.51 & 0.5 & \\
\hline 216 & $\mathrm{C}_{12} \mathrm{H}_{24} \mathrm{O}_{3}$ & 27.016 & 0.31 & 0.31 & 1,3-Pentanediol, 2,2,4-trimethyl-, \\
\hline & & 27.523 & 0.29 & 0.29 & \\
\hline & & 27.601 & 0.42 & 0.41 & \\
\hline 336 & $\mathrm{C}_{20} \mathrm{H}_{26} \mathrm{~F}_{2} \mathrm{O}_{2}$ & 31.363 & 2.81 & 3.1 & 2-Tridecynyl 2,6-difluorobenzoate \\
\hline 206 & $\mathrm{C}_{14} \mathrm{H}_{22} \mathrm{O}$ & 31.643 & 1.75 & 2 & 2,4-Di-tert-butylphenol \\
\hline & & 32.057 & 3.11 & 3.17 & \\
\hline & & 32.334 & 0.26 & 0.19 & \\
\hline 194 & $\mathrm{C}_{11} \mathrm{H}_{14} \mathrm{O}_{3}$ & 32.73 & 0.32 & 0.22 & Benzoic acid, 4-ethoxy-, ethyl ester \\
\hline & & 32.86 & 0.21 & 0.25 & \\
\hline & & 33.111 & 0.28 & 0.27 & \\
\hline & & 33.826 & 0.85 & 1.2 & \\
\hline & & 36.207 & 0.07 & 0.12 & \\
\hline 286 & $\mathrm{C}_{16} \mathrm{H}_{30} \mathrm{O}_{4}$ & 38.297 & 0.15 & 0.22 & 2,2,4-Trimethyl-1,3-pentanediol \\
\hline & & 39.563 & 0.12 & 0.23 & \\
\hline & & 41.192 & 0.12 & 0.24 & \\
\hline & & 42.634 & 0.36 & 0.22 & \\
\hline & & 44.176 & 0.12 & 0.21 & \\
\hline
\end{tabular}

The $\%$ area and $\%$ height is expressed as a $\%$ of the total area under all chromatographic peaks or $\%$ of the total height of all peaks respectively. 
Table 4: GC-MS headspace analysis of the $T$. grandiflora nut methanolic extract, elucidation of empirical formulas and putative identification (where possible) of each compound

\begin{tabular}{|c|c|c|c|c|c|}
\hline Molecular Mass & Molecular Formula & $\begin{array}{l}\text { Retention Time } \\
(\min )\end{array}$ & Area\% & Height\% & Putative Identification \\
\hline \multirow[t]{2}{*}{151} & \multirow[t]{2}{*}{$\mathrm{C}_{8} \mathrm{H}_{9} \mathrm{NO}_{2}$} & 11.073 & 24.94 & 14.96 & \multirow[t]{2}{*}{ Methyl N-hydroxybenzene carboximidoate } \\
\hline & & 12.927 & 6.35 & 5.28 & \\
\hline 118 & $\mathrm{C}_{6} \mathrm{H}_{14} \mathrm{O}_{2}$ & 14.502 & 1.53 & 1.25 & Ethanol, 2-(1,1-dimethylethoxy)- \\
\hline 130 & $\mathrm{C}_{8} \mathrm{H}_{18} \mathrm{O}$ & 15.371 & 0.48 & 0.54 & 2-ethyl-1-Hexanol \\
\hline \multirow{4}{*}{142} & \multirow{4}{*}{$\mathrm{C}_{9} \mathrm{H}_{18} \mathrm{O}$} & 17.866 & 0.64 & 0.84 & \multirow{4}{*}{ Nonanal } \\
\hline & & 18.053 & 1.23 & 1.56 & \\
\hline & & 18.178 & 4.34 & 5.47 & \\
\hline & & 19.27 & 0.62 & 0.89 & \\
\hline \multirow{7}{*}{150} & & 20.051 & 0.26 & 0.37 & \multirow{7}{*}{ Ethyl benzoate } \\
\hline & & 21.085 & 0.25 & 0.18 & \\
\hline & & 21.243 & 0.35 & 0.42 & \\
\hline & $\mathrm{C}_{9} \mathrm{H}_{10} \mathrm{O}_{2}$ & 22.48 & 1.78 & 1.49 & \\
\hline & & 22.79 & 0.16 & 0.29 & \\
\hline & & 23.407 & 0.15 & 0.27 & \\
\hline & & 25.38 & 0.82 & 0.84 & \\
\hline 216 & $\mathrm{C}_{12} \mathrm{H}_{24} \mathrm{O}_{3}$ & 26.414 & 0.49 & 0.52 & 1,3-Pentanediol, 2,2,4-trimethyl-, 1-isobutyrate \\
\hline 206 & $\mathrm{C}_{14} \mathrm{H}_{22} \mathrm{O}$ & 31.629 & 1.44 & 1.6 & 2,4-Di-tert-butylphenol \\
\hline 194 & $\mathrm{C}_{11} \mathrm{H}_{14} \mathrm{O}_{3}$ & 32.045 & 1.49 & 1.55 & Benzoic acid, 4-ethoxy-, ethyl ester \\
\hline 204 & $\mathrm{C}_{15} \mathrm{H}_{24}$ & 33.018 & 0.78 & 1.06 & $\begin{array}{c}\text { Bicyclo[7.2.0]undec-4-ene, 4,11,11-trimethyl- } \\
\text { 8-methylene- (caryophyllene) }\end{array}$ \\
\hline \multirow[t]{2}{*}{286} & \multirow[t]{2}{*}{$\mathrm{C}_{16} \mathrm{H}_{30} \mathrm{O}_{4}$} & 33.812 & 1.04 & 1.47 & \multirow[t]{2}{*}{ 2,2,4-Trimethyl-1,3-pentanediol diisobutyrate } \\
\hline & & 37.642 & 0.2 & 0.4 & \\
\hline \multirow{7}{*}{334} & & 38.285 & 0.16 & 0.27 & \multirow{7}{*}{ Butyl octyl phthalate } \\
\hline & & 39.552 & 0.1 & 0.26 & \\
\hline & & 41.183 & 0.12 & 0.22 & \\
\hline & $\mathrm{C}_{20} \mathrm{H}_{30} \mathrm{O}_{4}$ & 42.399 & 0.67 & 0.59 & \\
\hline & & 42.616 & 0.27 & 0.29 & \\
\hline & & 43.8 & 0.15 & 0.12 & \\
\hline & & 44.162 & 0.34 & 0.27 & \\
\hline
\end{tabular}




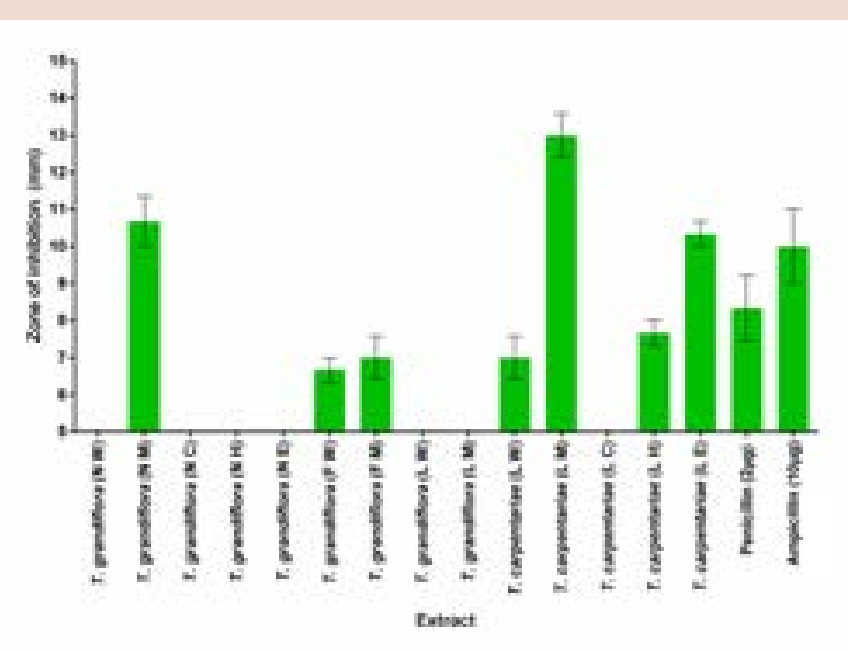

Figure 1: Growth inhibitory activity of Terminalia spp. extracts against the B. anthracis environmental isolate measured as zones of inhibition $(\mathrm{mm})$. $\mathrm{N}=$ nut; $\mathrm{F}=$ fruit; $\mathrm{L}=$ leaf; $\mathrm{W}=$ =aqueous extract $\mathrm{M}=$ methanolic extract; $\mathrm{C}=$ chloroform extract; $\mathrm{H}=$ hexane extract; $\mathrm{E}=$ =ethyl acetate extract. Results are expressed as mean zones of inhibition \pm SEM.

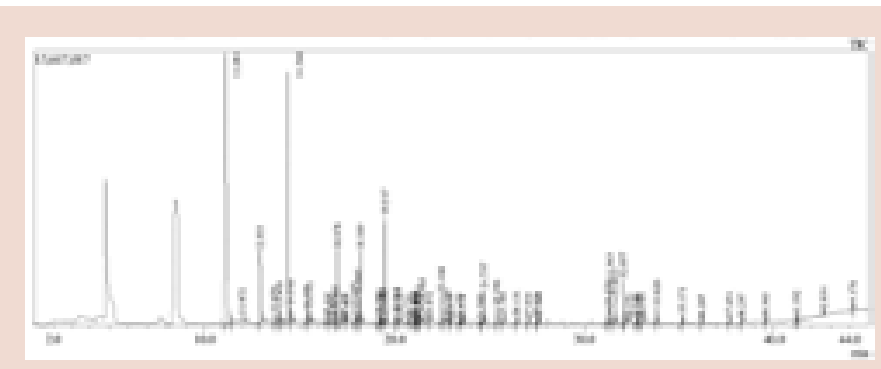

Figure 3: GC headspace chromatograms of $0.5 \mu \mathrm{L}$ injection of T. carpentariae leaf methanolic extract. The extract was dried and resuspended in methanol for analysis.

antibacterial properties. ${ }^{39}$ Of the Australian species, T. ferdinandiana has been the most extensively studied. Several studies have reported it to be a potent antibacterial agent, with growth inhibitory activity reported against a broad panel of bacterial pathogens, ${ }^{26}$ as well as against some bacterial triggers of rheumatoid arthritis ${ }^{23,25}$ and multiple sclerosis. ${ }^{24,25}$ Furthermore, T. ferdinandiana has also recently been reported to inhibit the proliferation of the gastrointestinal protozoan parasite Giardia duodenalis ${ }^{40}$ indicating its therapeutic potential against both prokaryotic and eukaryotic pathogens. Interestingly, whilst inhibition of B. anthracis growth was not evaluated in any of the previous studies, one recent study reported potent growth inhibition of the related bacterial species $B$. cereus, with MIC values as low as approximately $100 \mu \mathrm{g} / \mathrm{mL} .{ }^{26} B$. cereus is very closely related to $B$. anthracis with $>99 \% 16 \mathrm{~S}$ rRNA gene sequence homology ${ }^{41}$ and some bacterial taxonomonists believe that they should be classified as a single species under current standards ( $>97 \% 16$ S rRNA sequence homology). In contrast, other native Australian Terminalia spp. are less well studied.

The methanolic T. carpentariae leaf and T. grandiflora nutextracts displayed the most potent $B$. anthracis growth inhibitory activity (MIC values of 74 and $155 \mu \mathrm{g} / \mathrm{mL}$ respectively) and were therefore analysed by qualitative GC-MS. A number of interesting compounds were identified in each of these extracts. Analysis of the methanolic T. carpentariae leaf

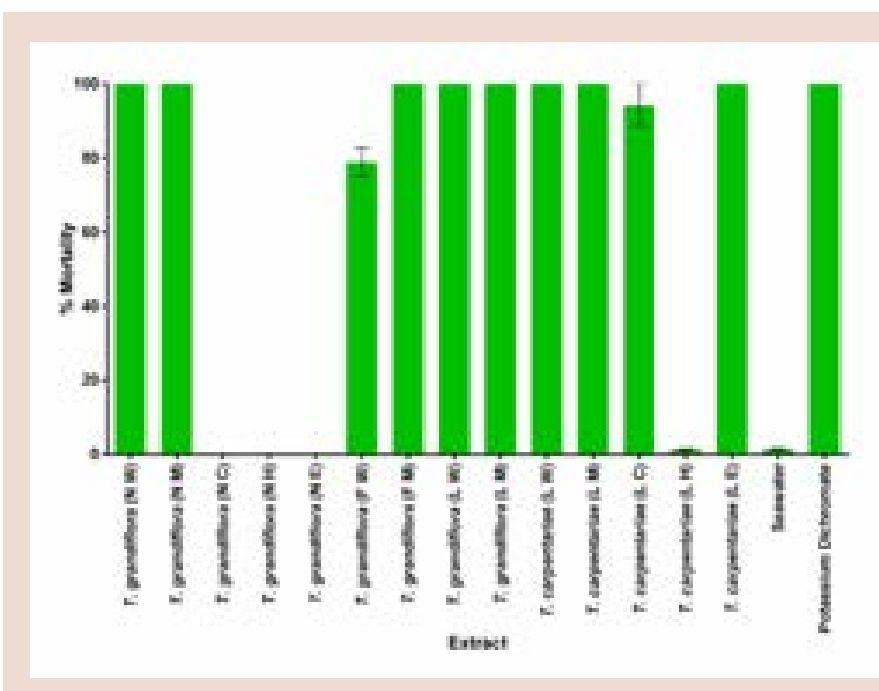

Figure 2: The lethality of Terminalia spp. extracts $(2000 \mu \mathrm{g} / \mathrm{mL})$ and the potassium dichromate $(1000 \mu \mathrm{g} / \mathrm{mL})$ and seawater controls towards A. franciscana nauplii after $24 \mathrm{~h}$ exposure. $\mathrm{N}=$ nut; $\mathrm{F}=$ fruit; $\mathrm{L}=\mathrm{leaf} ; \mathrm{W}=$ =aqueous extract $\mathrm{M}=$ methanolic extract; $\mathrm{C}=$ chloroform extract; $\mathrm{H}=$ hexane extract; $\mathrm{E}=$ ethyl acetate extract. Results are expressed as mean $\%$ mortality \pm SEM.

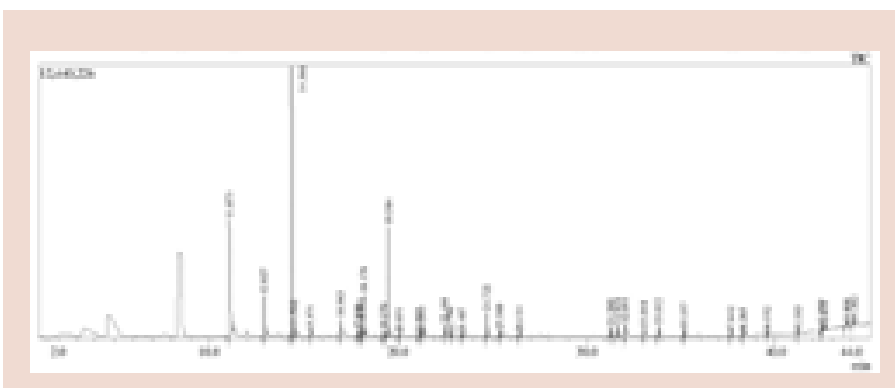

Figure 4: GC headspace chromatograms of $0.5 \mu \mathrm{L}$ injection of $T$. grandiflora nut methanolic extract. The extract was dried and resuspended in methanol for analysis.

extract putatively identified methyl N-hydroxybenzenecarboximidoate (Figure 5a), 1-octen-3-ol (Figure 5b), 5-hepten-2-one, 6-methyl- (Figure 5c), 2-tert-butoxyethanol (Figure 5d), 2-ethyl-1-hexanol (Figure 5e), dimethyl succinate (Figure 5f), isophorone (Figure 5g), a-citronellol (Figure 5h), nonanal (Figure 5i), 4-oxoisophorone (Figure 5j), ethyl benzoate (Figure 5k), methyl benzeneacetate (Figure 5l), a-terpineol (Figure 5m), 2-isopropylidene-3-methylhexa-3,5-dienal (Figure 5n), lauraldehyde (Figure 5o), 2,4-dimethyl-benzaldehyde (Figure 5p), 1,3-pentanediol, 2,2,4-trimethyl-, 1-isobutyrate (Figure 5q), 2,4-di-tert-butylphenol (Figure 5r), ethyl para-ethoxybenzoate (Figure 5s) and2,2,4-trimethyl-1,3pentanediol diisobutyrate (Figure $5 \mathrm{t}$ ). The presence of the monoterpenoids $\alpha$-citronellol and $\alpha$-terpineol are particular interesting as many monoterpenoids have potent broad spectrum antibacterial activity ${ }^{42}$ and therefore may contribute to the B. anthracis growth inhibition reported in our study. Interestingly, several monoterpenes have also been reported to suppress NF- $\kappa B$ signalling (the major regulator of inflammatory diseases). ${ }^{43,44}$ Thus, the terpene components may have a pleuripotent mechanism in blocking anthrax, by inhibiting the growth of the causative bacterium, as well as relieving the downstream inflammatory symptoms evident with the most common (cutaneous) form of the disease.

Many of the same compounds detected in the methanolic T. carpentariae leaf extract were also putatively identified in the methanolic T. grandi- 


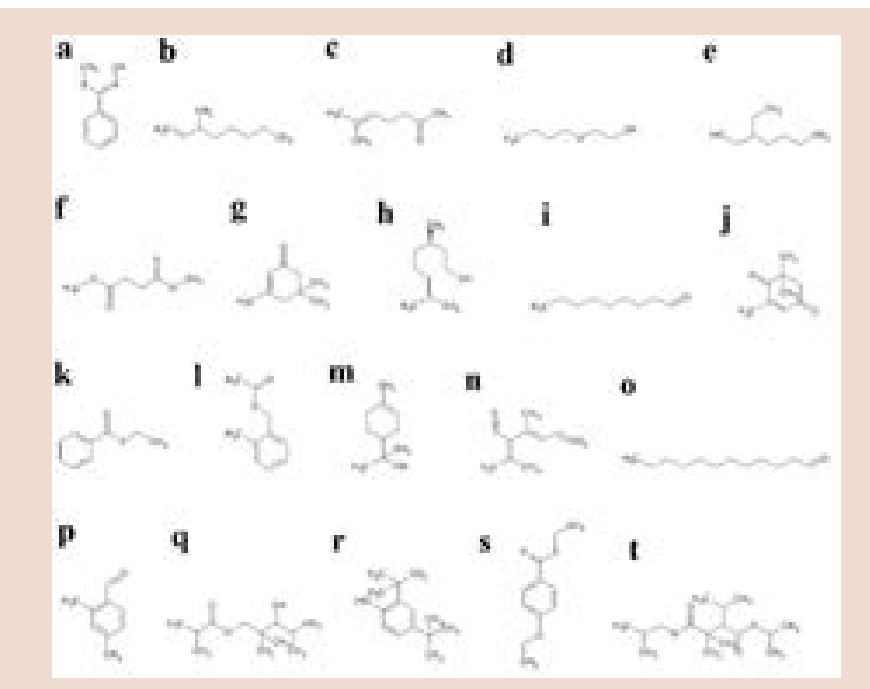

Figure 5: Methanolic T. carpentariae leaf components: (a) methyl N-hydroxybenzenecarboximidoate, (b) 1-octen-3-ol, (c) 5-hepten-2-one, 6-methyl-, (d) 2-tert-butoxyethanol, (e)2-ethyl-1-hexanol, (f) dimethyl succinate, (g)isophorone, (h) a-citronellol, (i) nonanal, (j) 4-oxoisophorone, (k) ethyl benzoate, (I) methyl benzeneacetate, (m) a-terpineol, (n) 2-isopropylidene-3-methylhexa-3,5-dienal, (o) lauraldehyde, (p) 2,4-dimethyl-benzaldehyde, (q) 1,3-pentanediol, 2,2,4-trimethyl-, 1-isobutyrate, (r) 2,4-di-tert-butylphenol, (s) ethyl para-ethoxybenzoate, (t) 2,2,4-trimethyl-1,3-pentanediol diisobutyrate.

flora nut extract. In particular, methyl N-hydroxybenzenecarboximidoate, 2-(1,1-dimethylethoxy)-ethanol, 2-ethyl-1-hexanol, nonanal, ethyl benzoate, 1,3-pentanediol, 2,2,4-trimethyl-,1-isobutyrate, 2,4-di-tertbutylphenol and benzoic acid, 4-ethoxy-ethyl ester were also present in the methanolic T. grandiflora nut extract. GC-MS analysis also putatively identified 2-(1,1-dimethylethoxy)-ethanol (Figure 6a), caryophyllene (Figure 6b), 2,2,4-trimethyl-1,3-pentanediol diisobutyrate (Figure 6c) and butyl octyl phthalate (Figure $6 \mathrm{~d}$ ) in the methanolic T. grandiflora nut extract. Previous studies have reported bacterial growth inhibitory activities for the sesquiterpenoid caryophyllene. ${ }^{42}$ It is likely that caryophyllene therefore contributes (at least in part) to the growth inhibitory activity of this extract.

It is likely that other phytochemical classes also contribute to the growth inhibitory properties of these extracts. Our qualitative phytochemical screening studies indicate that polyphenolics, flavonoids, saponins, and tannins were present in the methanolic T. carpentariae leaf and T. grandiflora nut extracts. However, no compounds of these classes were identified by GC-MS headspace analysis. As GC-MS techniques generally only detect lower polarity compounds, many mid to higher polarity bioactive compounds may have been missed. Recent studies have reported the LCMS profiles of extracts prepared from other Australian Terminalia spp. ${ }^{23-}$ ${ }^{25,40}$ Several features were common to all of these studies. In particular, all of these studies reported on the diversity of tannins in the Terminalia extracts. This is noteworthy as tannins have potent growth inhibitory activity against a broad spectrum of bacterial species. ${ }^{39}$ Recent studies have also highlighted the stilbene components in extracts prepared from different Australian Terminalia spp. ${ }^{24,25}$ Resveratrol and the glycosylated resveratrol derivative piceid, and several combretastatins were putatively identified in those studies. Stilbenes have attracted much recent interest due to their reported potent ability to of some compounds to block cancer cell progression and induce apoptosis by binding intracellular tubulin, thereby disrupting microtubule formation. ${ }^{45}$ Further studies utilising LC-MS are required to identify the mid to higher polarity compounds

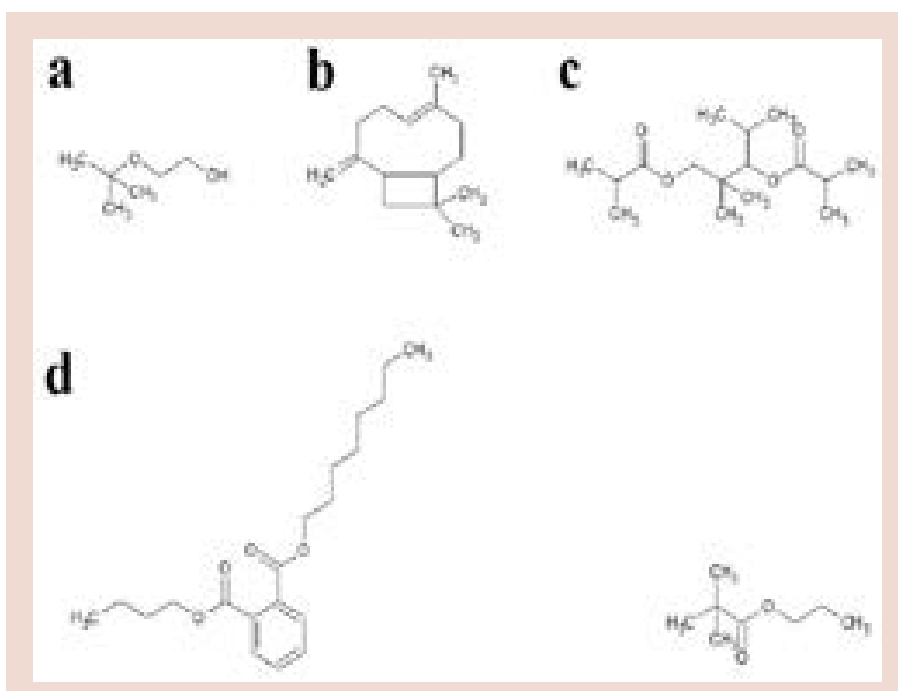

Figure 6: Methanolic T. grandiflora nut components not also detected in the methanolic T. carpentariae leaf extract: (a) 2-(1,1-dimethylethoxy)-ethanol, (b) caryophyllene, (c) 2,2,4-trimethyl-1,3-pentanediol diisobutyrate, (d) butyl octyl phthalate.

in the methanolic T. carpentariae leaf and T. grandiflora nut extract for a more complete understanding of the complete plant metabolome.

Of note, the methanolic T. carpentariae leaf extract was determined to be nontoxic towards Artemia franciscana nauplii, with $\mathrm{LC}_{50}$ values $>1000$ $\mu \mathrm{g} / \mathrm{mL}$. Extracts with $\mathrm{LC}_{50}$ values $>1000 \mu \mathrm{g} / \mathrm{mL}$ towards Artemia nauplii are defined as being nontoxic. ${ }^{38}$ This indicates that this extract may be safe for use for all forms of the disease (cutaneous, inhalation or gastrointestinal). In contrast, the methanolic T. grandiflora nut extract (which also was a potent inhibitor of $B$. anthracis growth) displayed toxicity towards Artemia nauplii, with an $\mathrm{LC}_{50}$ value of $740 \mu \mathrm{g} / \mathrm{mL}$. This represents low to moderate toxicity and indicates that this using human cell lines are required to further evaluate the safety of these extracts. Furthermore, whilst the results of our study are promising, it must be noted that the growth inhibitory studies screened against vegetative cells. As Bacillus spp. are spore formers, further studies are required to determine whether extracts with $B$. anthracis growth inhibitory activity also affect bacterial growth from the spores.

\section{CONCLUSION}

The $B$. anthracis growth inhibitory activity and low toxicity of the T. carpentariae and T. grandiflora extracts demonstrate their potential in the prevention and treatment of anthrax. Methanolic T. carpentariae leaf and T. grandiflora nut extracts were particularly potent growth inhibitors. Further investigations aimed at the purification of the bioactive components are needed to assess the mechanisms of action of these agents.

\section{ACKNOWLEDGEMENTS}

Financial support for this work was provided by the Environmental Futures Research Institute and the School of Natural Sciences, Griffith University, Australia. The authors are most grateful to David Boehme of Wild Harvest, Northern Territory, Australia for providing the Terminalia spp. used in these studies.

\section{CONFLICTS OF INTEREST}

The authors report no conflicts of interest. 


\section{ABBREVIATIONS USED}

DMSO: Dimethyl sulfoxide; $\mathbf{L C}_{50}$ : The concentration required to achieve 50 \% mortality; MIC: Minimum inhibitory concentration; PYE: Peptone yeast extract.

\section{REFERENCES}

1. Elad D. An unholy disease in the Holy Land: The history of anthrax between the Jordan River and the Mediterranean Sea (1909-2012). The Veterinary Journal. 2014;199(3):319-23.

2. Sternbach G. The History of Anthrax. The Journal of Emergency Medicine. 2003;24(4):463-7.

3. Ehrenkranz NJ, Sampson DA. Origin of the Old Testament Plagues: Explications and Implications. Yale Journal of Biology and Medicine. 2008;81(1):31-42.

4. Hampson K, Lembo T, Bessell P. Predictability of anthrax infection in the Serengeti, Tanzania. Journal of Applied Ecology. 2011;48(6):1333-44.

5. Dixon TC, Meselson M, Guillemin J. Anthrax. The New England Journal of Medicine. 1999;341(22):815-26

6. Watson A, Keir D. Information on which to base assessments of risk from environments contaminated with anthrax spores. Epidemiology and Infection. 1994;113(3):479-90

7. Ireland JAW, Hanna PC. Macrophage-Enhanced Germination of Bacillus anthracis Endospores Requires ger S. Infection and Immunity. 2002;70(10):5870-2.

8. Leppla SH, Robbins JB, Schneerson R. Development of an improved vaccine for anthrax. The Journal of Clinical Investigation. 2002;110(2):141-4

9. Athamna A, Athamna M, Abu-Rashed N. Selection of Bacillus anthracis isolates resistant to antibiotics. Journal of Antimicrobial Chemotherapy. 2004; 54(2):424-8

10. Aneja KR, Sharma C, Joshi R. Antimicrobial activity of Terminalia arjuna Wight and Arn: An ethnomedicinal plant against pathogens causing ear infection. Brazilian Journal of Otorhinolaryngology. 2012;78(1):68-74.

11. Shinde SL, Junne SB, Wadje SS, Baig MMV. The diversity of antibacterial compounds of Terminalia species (Combretaceae). Pakistan Journal of Biological Sciences. 2009;12(22):1483-6.

12. Chopra RN, Nayar SL, Chopra IC. Glossary of Indian Medicinal Plants. New Delhi, CSIR. 1956.

13. Nadkarni AK. Terminalia chebula. In: Dr. K.M. Nadkarni's Indian Materia Medica, $3^{\text {rd }}$ ed., Bombay, Popular Prakashan Pvt. Ltd. 1976;1202-11.

14. Das B. Materia Medica of Ayurveda. New Delhi Jain Publishers. 1991;8.

15. Aneja KR, Joshi R. Evaluation of antimicrobial properties of fruit extracts of Terminalia chebula against dental caries pathogens. Jundishapur Journal of Microbiology. 2009;2(3):105-11.

16. Mbwambo ZH, Erasto $\mathrm{P}$, Nondo RO. Antibacterial and cytotoxic activities of Terminalia stenostachya and Terminalia spinosa. Tanzania Journal of Health Research. 2011;13(2):1-8

17. Cock IE, van Vuuren SF. The potential of selected South African plant extracts with anti-Klebsiella activity for the treatment and prevention of ankylosing spondylitis. Inflammopharmacology. 2015;23(1):21-35. DOI 10.1007/s10787014-0222-z

18. Cock IE, van Vuuren SF. South African food and medicinal plant extracts as potential antimicrobial food agents. Journal of Food Science and Technology. 2015; DOI 10.1007/s13197-015-1806-3

19. Cock IE, van Vuuren SF. Anti-Proteus activity of some South African medicinal plants: Their potential for the prevention of rheumatoid arthritis. Inflammopharmacology. 2014;22:23-36. DOI 10.1007/s10787-013-0179-3

20. Cock IE, van Vuuren SF. A comparison of the antimicrobial activity and toxicity of six Combretum and two Terminalia species from Southern Africa. Pharmacognosy Magazine. 2015;11(4):208-18. DOI 10.4103/0973-1296.149740

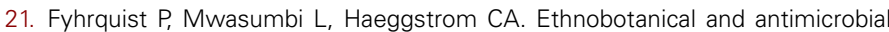
investigation onsome species of Terminalia and Combretum (Combretaceae) growing in Tanzania. Journal of Ethnopharmacology. 2002;79(2):169-77.

22. Dhetchuvi M, Lejoly J. Contribution a' la connaissance ds plantesme'dicinales du Nord-Est du Zaire. Mitt Inst Allg Bot Hamburg.1990;23b:991-1006.

23. Sirdaarta J, Matthews B, Cock IE. Kakadu plum fruit extracts inhibit growth of the bacterial triggers of rheumatoid arthritis: Identification of stilbene and tannin components. Journal of Functional Foods. 2015;17:610-20. DOI: 10.1016/j. jff.2015.06.019
24. Sirdaarta J, Matthews B, White A, et al. GC-MS and LC-MS analysis of Kakadu plum fruit extracts displaying inhibitory activity against microbial triggers of multiple sclerosis. Pharmacognosy Communications. 2015;5(2):100-15. DOI: 10.5530/pc.2015.2.2

25. Courtney R, Sirdaarta J, Matthews B, et al. Tannin components and inhibitory activity of Kakadu plum leaf extracts against microbial triggers of autoimmune inflammatory diseases. Pharmacognosy Journal. 2015;7(1):18-31. DOI: 10.5530/pj.2015.7.2

26. Cock IE, Mohanty S. Evaluation of the antibacterial activity and toxicity of Terminalia ferdinandia fruit extracts. Pharmacognosy Journal. 2011;3(20):72-9.

27. Cock IE. Medicinal and aromatic plants-Australia, in Ethnopharmacology section, Biological, Physiological and Health Sciences, Encyclopedia of Life Sup port Systems (EOLSS),2011; Developed under the Auspices of the UNESCO, EOLSS Publishers, Oxford ,UK, (http://www.eolss.net).

28. Kalt FR, Cock IE. Gas chromatography-mass spectroscopy analysis of bioactive Petalostigma extracts: Toxicity, antibacterial and antiviral activities. Pharmacognosy Magazine. 2014;10(37 Supp):S37-S49. DOI: 10.4103/0973-1296.127338

29. Sautron C, Cock IE. Antimicrobial activity and toxicity of Syzygium australe and Syzygium leuhmannii fruit extracts. Pharmacognosy Communications. 2014;4(1):53-60. DOI: 10.5530/pc.2014.1.8

30. Vesoul J, Cock IE. The potential of Bunya nut extracts as antibacterial functional foods. Pharmacognosy Communications. 2012;2(1):72-9. DOI: 10.5530/ pc.2012.1.13

31. Wright $\mathrm{MH}$, Matthews $\mathrm{B}$, Greene $\mathrm{AC}$, et al. Growth inhibition of the zoonotic bacteria Bacillus anthracis by high antioxidant Australian plants: New leads for the prevention and treatment of anthrax. Pharmacognosy Communications. 2015;5(3):173-89. DOI: 10.5530/pc.2015.3.3

32. Winnett $\mathrm{V}$, Boyer $\mathrm{H}$, Sirdaarta $\mathrm{J}$, et al. The potential of Tasmannia lanceolata as a natural preservative and medicinal agent: Antimicrobial activity and toxicity. Pharmacognosy Communications. 2014;4(1):42-52. DOI: 10.5530/pc.2014.1.7

33. Kalt FR, Cock IE. The medicinal potential of Australian native plants from Toohey Forest, Australia. The South Pacific Journal of Natural Science. 2011;28:41-7. DOI: $10.1071 /$ SP10003

34. Arkhipov A, Sirdaarta J, Rayan P, et al. An examination of the antibacterial, antifungal, anti-Giardial and anticancer properties of Kigelia africana fruit extracts. Pharmacognosy Communications. 2014:4(3):62-76. DOI: 10.5530/pc.2014.3.7

35. Cock IE. Antimicrobial activity of Acacia aulacocarpa and Acacia complanta methanolic extracts. Pharmacognosy Communications. 2012;2(1):66-71. DOI: 10.5530/pc.2012.1.12

36. Cock IE. Assessment of the toxicity of selected Australian native plant extracts using the Artemia franciscana nauplii bioassay. Internet Journal of Toxicology. 2008;5:2

37. Ruebhart DR, Wikramasinghe WA, Cock IE. Protective efficacy of the antioxidants vitamin $\mathrm{E}$ and Trolox against Microcystis aeruginosa and microcystin-LR in Artemia franciscana nauplii. Journal of Toxicology and Environmental Health Part A. 2009;72(24):1567-75. DOI: 10.1080/15287390903232459

38. Cock IE, Ruebhart DR. Comparison of the brine shrimp nauplii bioassay and the ToxScreen-II test for the detection of toxicity associated with Aloe vera (Aloe barbadensis Miller) leaf extract. Pharmacognosy Research. 2009;1(2):98-101.

39. Cock IE. The medicinal properties and phytochemistry of plants of the genus Terminalia (Combretaceae). Inflammopharmacology. 2015;23(5):203-29. DOI 10.1007/s 10787-015-0246-z

40. Rayan P, Matthews B, McDonnell PA, et al. Terminalia ferdinandiana extracts as inhibitors of Giardia duodenalis proliferation: a new treatment for giardiasis. Parasitology Research. 2015;114(7):2611-20. DOI 10.1007/s00436-015-4465-4

41. Maughan H, Van der Auwera G. Bacillus taxonomy in the genomic era finds phenotypes to be essential though often misleading. Infection Genetics and Evolution. 2011;11(5):789-97

42. Cock IE. The phytochemistry and chemotherapeutic potential of Tasmannia lanceolata (Tasmanian pepper): A review. Pharmacognosy Communications. 2013;3(4):13-25.

43. Salminen A, Lehtonen M, Suuronen T. Terpenoids: Natural inhibitorsof NF-KB signalling with anti-inflammatory and anticancer potential. Cellular and Molecular Life Sciences. 2008;65(19):2979-99.

44. Zhou JY, Tang FD, Mao GG. Effect of a-pinene on nucleartranslocation of NF-kB in THP-1 cells. Acta Pharmacology Sinica. 2004;25(4):480-4.

45. Dark GG, Hill SA, Prise VE. Combretastatin A-4, an agent that displays potent and selective toxicity toward tumor vasculature. Cancer Res. 1997:57(10):1829-34. 


\section{PICTORIAL ABSTRACT}

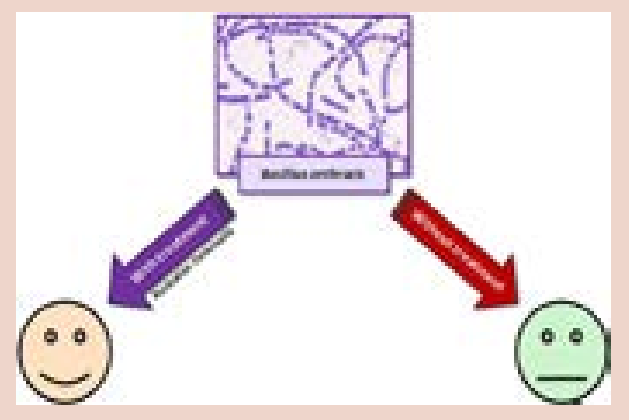

\section{SUMMARY}

- T. carpentariae and T. grandiflora extracts inhibited Bacillus anthracis growth in vitro.

- The methanolic T. carpentariae leaf and T. grandiflora nut extracts were particularly potent growth inhibitors with MIC's of 74 and $155 \mu \mathrm{g} / \mathrm{mL}$ respectively.

- Generally, the inhibitory Terminalia extracts were either non-toxic or low toxicity in the Artemia nauplii assay.

- GC-MS headspace profiling of the inhibitory extracts revealed distinct phytochemical profiles for the T. carpentariae and T. grandiflora extracts.

- Phytochemical profiling highlighted several nonpolar compounds as potentially contributing to the $B$. anthracis growth inhibitory activity.

\section{ABOUT AUTHORS}

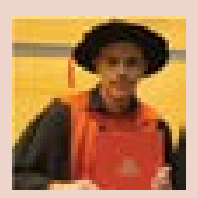

Dr Mitchell Henry Wright: Received his PhD in 2014, for his work investigating the manganese reduction and oxidation characteristics of environmental bacteria. He is currently a postdoctoral researcher at Griffith University, Australia, where he is working on several projects both in the areas of geomicrobiology and pharmocognosy. His present research interests are the use of biogenic manganese oxides in the bioremediation of metal-contaminated sites as well as the use of Australian native plants in the treatment and prevention of various pathogenic bacteria.

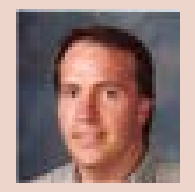

Dr Anthony Greene: Is a senior lecturer and researcher at Griffith University, Brisbane Australia. He obtained his PhD in Microbiology from the University of New South Wales and focuses on extreme environments, bioremediation and Geomicrobiology. His specific interests include the microbial ecology of thermophilic, saline and alkaliphilic environments and the mechanisms and industrial potential of extremophilic bacteria contained therein.

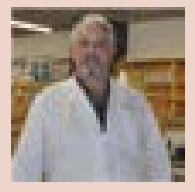

Dr lan Cock: Leads a research team in the Environmental Futures Research Institute and the School of Natural Sciences at Griffith University, Australia. His research involves bioactivity and phytochemical studies into a variety of plant species of both Australian and international origin including Aloe vera, South Asian and South American tropical fruits, as well as Australia plants including Scaevola spinescens, Pittosporum phylliraeoides, Terminalia ferdinandiana (Kakadu plum), Australian Acacias, Syzygiums, Petalostigmas and Xanthorrhoea johnsonii (grass trees). This range of projects has resulted in nearly 200 scientific publications in a variety of peer reviewed journals. 